\title{
Design Hybrid Intelligent system for Cattle Diseases Diagnosis and Treatment
}

\author{
Safwan O. Hasoon ${ }^{1}$ \\ Ibrahim Ahmed Saleh²: i.hadedi@uomosul.edu.iq \\ Baydaa Sulaiman Bahnam ${ }^{3}$ Baydaa_sulaiman@uomosul.edu.iq \\ ${ }^{123}$ College of Computer Sciences and Mathematics /University of Mosul/Iraq \\ Author for Correspondence: Safwan O. Hasoon:Dr.safwan1971@uomosul.edu.iq
}

\begin{abstract}
Cattle is one of the main concerns of people and companies in various countries of the world. This paper built the architecture of the cattle diseases by combining the characteristics of an expert system with a neural network Expert system focuses on diagnosing the possible diseases that affect the life of cattle through constructing knowledge bases. While the Radial base functions, a neural network is proposed for the cattle diseases treatments. A tightly coupled model is used to implement a hybrid intelligence technique for diagnosing and Treatment cattle diseases. The result generated by the system was enough to demonstrate its performance.
\end{abstract}

Keywords. Expert system, Cattle diseases; Radial base function, Neural network

\section{Introduction}

The EXPERT system applies artificial intelligence(AI) technical based on one or more knowledge. Experts provide it to analyze and solve problems in specific areas knowledge, experience and methods, summarizing and forming rules, using software Implemented and then stored. The system interacts with the user according to the user response procedure. The data, information, or facts provided by the inquiry, using the system storage Home knowledge and experience, making inferential judgments, simulating human experts to solve problems[1]. Form the process of decision making, finally draw conclusions, give recommendations, and give The credibility of this conclusion is for the user's decision reference [1-2]. It can solve Experts who need experts to solve complex problems, Solutions, or decisions that greatly improve the management and decision of all kinds of things Policy level, moving towards the high-level system goals that humans expect [2].

Expert system in the field of aquatic products started in the early 1990s in aquaculture research and development of some experts in the field of disease, disease diagnosis, fishery resource assessment, etc. system [3], such as the networked freshwater shrimp culture expert system [4], fish disease diagnosis and prevention expert system [5-6], fishery resource assessment Home system, in terms of system function, interactivity, operability, etc. Some progress has been made. Aquaculture operators Computer processing systems use this system for production planning, aquaculture management, and economic analysis [7].

Diagnostics Knowledge has the characteristics of uncertainty, complexity, and ambiguity. It needs data to simulate the non-linear mapping between symptoms and the syndromes model fully. The Artificial Neural Network (ANN) is a network of interconnected processing units (neurons) that abstracts, simplifies, and simulates the human brain [8]. ANN has a non-linear mapping function, which, using automated input learning, can approximate any complicated non-linear mapping with arbitrary precision and output samples, so it is suitable for modelling the reasoning process of TCM diagnosis.Hao Yanchao [9] used the neural network method to construct a knowledge 
base for the eight-dimensional syndrome differentiation of TCM tongue diagnosis. The study is based on the correspondence between the "lingual image" and the "eight classes" of Chinese medicine (including table, inner, cold, heat, virtual, real, etc.), and establishes "probabilistic neural network" and "generalized regression neural network" and Three types of neural networks, such as "learning vector quantization neural network", are tried and used for TCM diagnostic reasoning. In addition, Wang Yan et al. [10] also used the ANN algorithm to construct a TCM Tongue diagnosis knowledge base. The relationship between the predicted tongue image and the eight-class syndrome is consistent with the clinical diagnosis results (errors in individual attributes). These work descriptions are feasible using neural network technology to build a TCM diagnostic knowledge base.

When employed independently, expert systems and neural networks are beneficial in specialized fields; however, they are occasionally given restricted solutions to deal with specific challenges. By combining expert systems with neural networks, researchers have attempted to attain or totally merge the best qualities of each [11]. This paper designed a hybrid expert system for cattle disease that used the expert system to diagnose from the rules with an inference engine while the neural network finds the appropriate treatment of the database.

\section{Related work}

Expert system is an important research topic for researchers in computer science. Next, are reviewed some researches in this field:

- In 2014, Abbas Sheikhtaheri[12] is designed a knowledge base system with connectionists for the medical field; they applied backpropagation connectionists to reduce search time to find the intelligent advice process.

In 2015, Zeinab Abrishami and Hamid Tabatabaee [13] used two Artificial intelligence methods with a knowledge base system; they designed a fuzzy expert system with a multi-layer connectionist to diagnose hypertension. The whole system uses a set of rules, tests, physical signs, and laboratory analysis to provide different suggestions for analyzing diseases.

- In 2017, Ahmad Zamsuriand, with some researchers [14], designed a cattle Disease knowledge base system to diagnosis with forwarding Chaining technique to ease disease diagnosis and displaying the information about the Cattles itself and design a prototype system used forward chaining technique, which is used as a knowledge base in asking questions to farmers.

- In 2018, Murali Ravuri[15], with other researchers as the starting point for combining expert knowledge with knowledge acquired from a different data store, such as electronic health records methods, to combine approaches to improve accuracy and flexibility. In the same year, Batista L. Oliveira [16] combined three techniques with a knowledge base system, fuzzy, connectionist with SQL instruction to detect attacks and increase the concern with the security of this environment. The methods called to conclude the results of the experiments prove to construct a prototype system to encourage the development of intelligent apps in order to avoid cyber-attacks.

\section{Cattle diseases}

To design an expert system, there are some cattle diseases, and detailed information about them are listed for following

\section{Rinder Pest}

2. Goat Plague or Peste

3. Pox

4. Boine Viral Diarrhea BVD

5. Foot And Mouth Disease F.M.D

6. Rift Valley Fever

7. Tuberculosis

8. Hormones 


\section{Ringworm}

10. Foot and mouth disease

11. Hemorrhagic hemorrhagic poisoning

12. Listeriosis[17]

\section{DESIGN PROPOSED SYSTEM}

This paper introduces an intelligent system that hybrids two components of intelligence techniques: an expert system and an artificial neural network (ANN). The intelligent system's first level is the expert system.

\subsection{Expert system}

The expert system is used to diagnose the diseases according to the knowledge base, while the RBF neural network is applied to find the treatment states for the diseases. The proposed system is illustrated in (Fig.1).

The system uses a case base to store information from observations of human experts' choices and hypotheses; the case base is also updated as the system is used to view instances of expert performance. The inference engine is the heart of a hybrid system that uses blind search techniques to apply rules for diseases diagnosis and treatment. The forward chaining (data-driven reasoning) is used for problem-solving when data (symptoms of the diseases) are a starting point.

The user interface is the language interface, with which the user can access to a hybrid system by getting answers to problems.

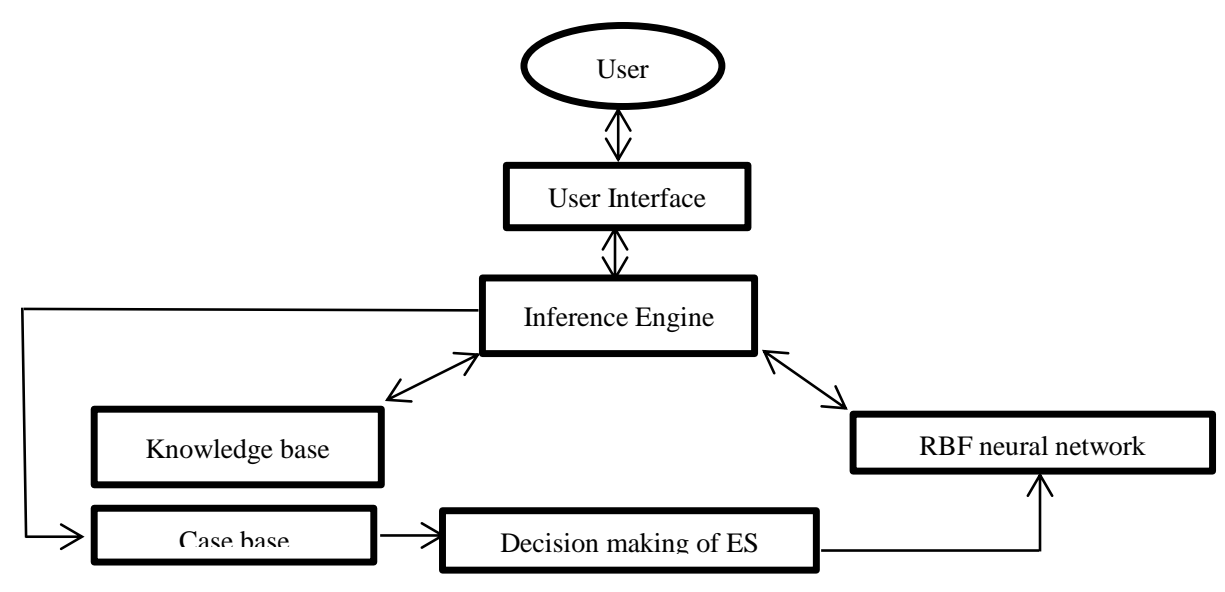

Fig. 1. Hybrid intelligent system structure

The knowledge base is most important of an expert system. It is composed of domains and heuristic-based upon experience and consist of fact and rules for cattle disease, as shown in Table 1.

Table 1: Knowledge base (Rules) for cattle diseases.

\begin{tabular}{|l|l|l|}
\hline No & Condition & Action \\
\hline & If $\begin{array}{l}\text { Sudden rise of temperature up to } 40^{\circ} \mathrm{C} \text { and Curvature of the } \\
\text { back and Hearing the teeth squeak and Existence of } \\
\text { secretions of the nose and runny tears and appearance of } \\
\text { small ulcers in the membranes of the mouth and reproductive } \\
\text { system and diarrhea after the appearance of sores and drop } \\
\text { the temperature and diarrhea develops and is mucus mixed } \\
\text { with blood }\end{array}$ & Then Rinder Pest \\
& & \\
\hline
\end{tabular}




\begin{tabular}{|c|c|c|}
\hline 2 & $\begin{array}{l}\text { If A sudden rise in temperature up to } 41-42^{\circ} \mathrm{C} \text { and Idle and do } \\
\text { not eat and Inflammation of mucous membranes by mouth } \\
\text { and nose and Eyelid adhesion and severe diarrhea may be } \\
\text { accompanied by blood }\end{array}$ & Then Goat Plague or Peste \\
\hline 3 & $\begin{array}{l}\text { If } \text { General bleeding and high temperature and appearance of } \\
\text { a skin rash in the form of granules and contains a liquid in } \\
\text { many parts of the body, These granules dry up and } \\
\text { become stiff and crusty, and Sores are present in all parts of } \\
\text { the diet and death occurs at any stage of the disease }\end{array}$ & Then Pox \\
\hline 4 & $\begin{array}{l}\text { If Wasting and high Fever and presence of ascites between the } \\
\text { jaws of the animal and disappear with diarrhea and Low } \\
\text { milk production and Thirst and The wool falls into the } \\
\text { sheep and diarrhea is a clear sign of the disease and increase } \\
\text { the thickness of the intestinal wall to four times and } \\
\text { Inflammation of lymph nodes }\end{array}$ & Then Boine Viral Diarrhea BVD \\
\hline 5 & $\begin{array}{l}\text { If } \text { High temperature up to } 40^{\circ} \mathrm{C} \text { and Stop the process of } \\
\text { procrastination and refrain from eating and The presence of } \\
\text { ulcers in the mouth, legs, legions, and tongue The incidence } \\
\text { of lameness due to the presence of ulcers and Abortion } \\
\text { occurs The animal moves its tongue in and out of the mouth } \\
\text { abnormally }\end{array}$ & $\begin{array}{l}\text { Then Foot and Mouth Disease } \\
\text { FMD }\end{array}$ \\
\hline 6 & $\begin{array}{l}\text { If Rapid death of small animals within } 36 \text { hours and High } \\
\text { temperature and difficulty breathing, and The presence of } \\
\text { necrosis in the liver }\end{array}$ & Then Rift Valley Fever \\
\hline 7 & $\begin{array}{l}\text { If High temperature and Anorexia and Dry diarrhea and exit of } \\
\text { blood with pulmonary secretions and Breathing speed and } \\
\text { Severe diarrhea with swelling in the stomach and } \\
\text { Inflammation of the lactic glands and Change the color } \\
\text { of milk }\end{array}$ & Then Tuberculosis \\
\hline 8 & $\begin{array}{l}\text { If Anemia and General weakness and Dung is dark brown and } \\
\text { Idle and lack of productivity }\end{array}$ & Then Hormones \\
\hline 9 & $\begin{array}{l}\text { If } \text { Fever and high temperature up to } 41 \text { and Cough and } \\
\text { discharge from the nasal nose and Front legs are close } \\
\text { together and The fluidity of games and diarrhea and Abortion } \\
\text { and sometimes for pregnant women and Arthritis and } \\
\text { lameness and The appearance of swelling in the skin and } \\
\text { presence of fibrointestinal filaments linking the bile } \\
\text { membrane and thoracic cage }\end{array}$ & Then Ringworm \\
\hline 10 & $\begin{array}{l}\text { If The infected animal is then warmed for between } 24 \text { and } 36 \\
\text { hours and The infected animal's mouth swells and the saliva } \\
\text { is soaked from the infected animal's mouth, and Bubbles are } \\
\text { spread in the mouth, pharynx, and gums, and It usually } \\
\text { explodes and leaves painful, inflamed ulcers and he same } \\
\text { bubbles appear on the feet and Jitter and Decrease in milk } \\
\text { production }\end{array}$ & Then Foot and mouth disease \\
\hline
\end{tabular}




$11 \quad$\begin{tabular}{l|l|l|}
\hline If $\begin{array}{c}\text { High temperature and difficulty breathing as a result of the } \\
\text { tumor Ondimip neck and zodiac and strong and the lungs are } \\
\text { bloated and full and nominated from the nose with the } \\
\text { descent of blood-red color and tears and tears of the eye and } \\
\text { dead tissue on the lining of the membranes and } \\
\text { presence of vesicles spread under the skin neck and chest }\end{array}$ & Then Agic poisoning \\
Falling and then dying & \\
\hline
\end{tabular}

\subsection{RBF Neural Network}

The RBF neural network $[18,19]$ is the second stage used in the intelligent system to treat diseases, as shown in (Fig.2).

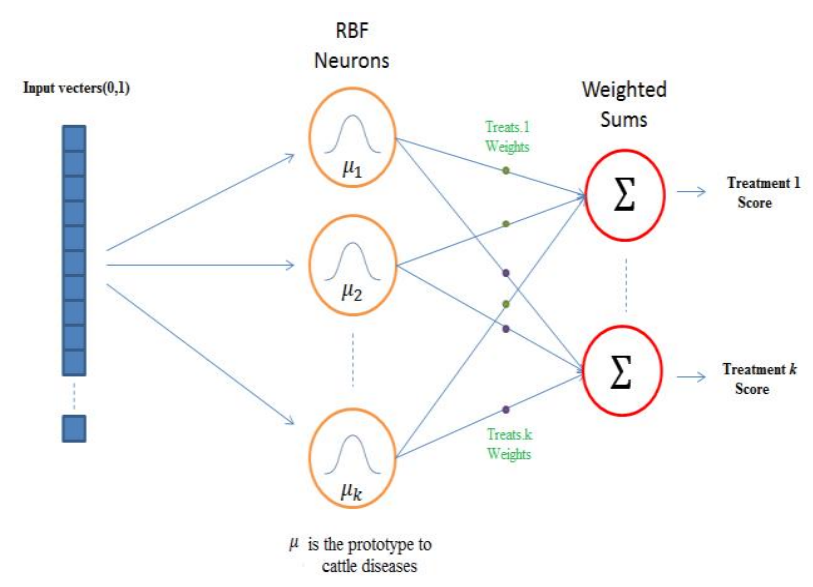

Fig. 2. RBF Neural network structure

use of neural networks to support the expert system for disease treatment has been proposed in this system. The neural network of RBF offers the proposed system. The network has the following features:

1. It completed the building and training processes in a single step.

2. It can quickly locate the classification's final results.

3. RBF is simple to construct, with only three layers (input layer for data, one hidden layer, and output layer for actual output).

4. RBF is hybrid learning; it can combine two types of learning algorithms, "supervised and unsupervised learning," with the first stage of the input layer to the hidden layer being unsupervised and the second stage being supervised.

Two types of activation functions are used in the RBF Neural network: the "Gaussian function" between inputhidden layers. The other is the "sign function" between hidden-output layers, while the initial weights are chosen randomly.

The second stage of the proposed system implemented a radial basis neural network used to treat cattle disease. The following steps explain how the RBF neural network works:

Srep1: input the cattle disease can be diagnosis mentioned by the first stage (Expert System), and randomly generate the initial weights. 
Step 2: transform the text data into binary. As a result, the RBF neural network can cope with data encoded as shown in Table2.

Table 2. Data set of RBF

\begin{tabular}{|l|l|l|l|l|}
\hline Data input & Target & code & Treatment \\
\hline NO & Diseases & 00001 & $\begin{array}{l}\text { Vaccine with protective booster } \\
\text { dose }\end{array}$ & 11110 \\
\hline 1 & Rinder Pest & 00010 & PPR vaccine & 11101 \\
\hline 2 & Goat Plague or Peste & 00011 & Live smallpox vaccine & 11100 \\
\hline 3 & Pox & 00100 & Pre - mating diarrhea & 11011 \\
\hline 4 & Boine Viral Diarrhea BVD & 00101 & Multiple fertilization altogether & 11010 \\
\hline 5 & Foot and Mouth Disease F.M.D & 00110 & MVP-22 vaccine & 11001 \\
\hline 6 & Rift Valley Fever & 00111 & $\begin{array}{l}\text { Test the TB and exclude the } \\
\text { injured }\end{array}$ & 11000 \\
\hline 7 & Tuberculosis & 01000 & & 10111 \\
\hline 8 & Hormones & 01001 & Tramsin in vein & 10110 \\
\hline 9 & Ringworm & 01010 & $\begin{array}{l}\text { The appropriate multivitamin } \\
\text { vaccine }\end{array}$ & 10101 \\
\hline 10 & Foot and mouth disease & 01011 & & 10100 \\
\hline 11 & agic poisoning & \multicolumn{2}{|}{} \\
\hline
\end{tabular}

Step 3: Broadcast the data through nodes in the input layer of RBF

Step 4: Move the data to nodes in the hidden layer using the Gaussian activation function from the first layer.

$$
g(x)=e^{-\|x-w\| / 2 * \sigma^{2}}
$$

Where:

$\mathrm{x}$ : is the input data.

$\mathrm{w}$ : is the weight of the first stage.

б: is the data speared control parameter.

Step 5: the result of the hidden layer is moved to the nodes in the output layer, and calculate the net value using eq.(2).

$$
\text { net }=\sum x_{i} y_{i}
$$

Step 6: Compute the actual output by applying eq. (3).

$$
Y=\operatorname{sign}\left[\sum_{1}^{n} x_{i} w_{i}-\theta\right]
$$

Step 7: change the weights of the RBF neural network if the actual output is different from to target value using eq.(3) and eq.(4). Otherwise, there is no change to the weights (i.e., optimal weights).

$$
e(p)=Y_{d}-Y_{p}
$$


where $\mathrm{p}=1,2,3 \ldots$

$$
w_{i}(p+1)=w_{i}(p)+a x_{i} * e(p)
$$

Step 8: Take output as a text representing the treatment of a specific disease.

\subsection{Neural network with the expert system}

The hybrid system combines the advantages of the traditional expert system with the neural networks and overcomes their disadvantages. Thus, there is a natural tendency to create a hybrid system depending on integrating the advantages of both techniques in [7]. A hybrid intelligent system is a way for combining many artificial techniques to build a more powerful system with better performance.

A mixed system that combines the expert system and the network is called a neurosis based on the rules of a neurologist system (or symbolic neural system). Neural networks are a "suitable" component for developing a new generation of expert systems since they satisfy high requirements like as learning, generalization, durability, and parallel processing of input.

A neural expert system is a hybrid system that combines an expert system and a neural network ( Neuro-Symbolic System). Neural networks are "suitable" components for developing a new breed of expert systems because they meet high system characteristics such as resilience, learning, generalization, robustness, and parallel information processing [11].

An inference engine, which infers over the neural knowledge base to manage the input flow, is the most important aspect of a neural expert system [11]. There are two types of integration strategies: physical integration and functional integration. The integration of expert systems and neural networks, as well as the capabilities of the neural expert system, are depicted in Table 1.

Integrating the rule-based system and neural network can produce $\mathrm{d}$ some specific advantages and disadvantages. The two techniques can be integrated to exploit the advantages and reduce the disadvantages of each technique used alone, as shown in Table 3.

Table 3: Neural expert system references

\begin{tabular}{|c|c|c|c|}
\hline Attributed & $\begin{array}{l}\text { Expert } \\
\text { System }\end{array}$ & $\begin{array}{c}\text { Neural } \\
\text { Network }\end{array}$ & $\begin{array}{l}\text { Neural } \\
\text { Expert } \\
\text { system }\end{array}$ \\
\hline $\begin{array}{c}\text { Knowledge } \\
\text { representation }\end{array}$ & ז & $\theta$ & كُ \\
\hline $\begin{array}{l}\text { Tolerance for } \\
\text { uncertainty }\end{array}$ & $\Theta$ & ţ & 象 \\
\hline $\begin{array}{l}\text { Tolerance for } \\
\text { Imprecision }\end{array}$ & $\theta$ & 负 & 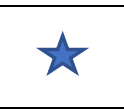 \\
\hline Ability to adapt & $\Theta$ & לָ & th \\
\hline The ability to learn & $\Theta$ & th & w \\
\hline Ability to explain & ל九 & $\Theta$ & 光 \\
\hline Maintainability & $\theta$ & 穴 & خح \\
\hline \multicolumn{4}{|c|}{$\begin{array}{l}\text { the terms used for grading are Weak } \\
\text { Excellent }\end{array}$} \\
\hline
\end{tabular}


The models for physical integration can generally be classified into five defined: as illustrated for the following $[18,19]$.

i. Loosely coupled systems;

ii. Tightly coupled systems;

iii. Fully integrated systems;

iv. Localist rule-based reasoning implementations;

v. Distributed rule-based reasoning implementations;

The closely coupled is employed when the database is accessed and shared directly by both expert systems and neural networks. It is divided into conceptual and microfeature (In other words, where representational knowledge is disseminated). At the concept level, the representation is a local list with one node for each idea, and at the microfeature level, it is a distributed list with a collection of nodes representing each concept. Rules are applied at the idea level, evidence is analyzed using weighted sums, with links between nodes representing conditions and nodes indicating conclusions. [18-21].

\section{Result and Discussion}

The system is operated through the main page shown in Fig. 3. As shown in the symptoms on the animal, the disease Diagnosis page has been successfully tested, making the complete system test that has identified the type of disease that will help the doctor in the diagnostic process. The

System test helped ensure the requirements and design conformance. Follow the system test procedure

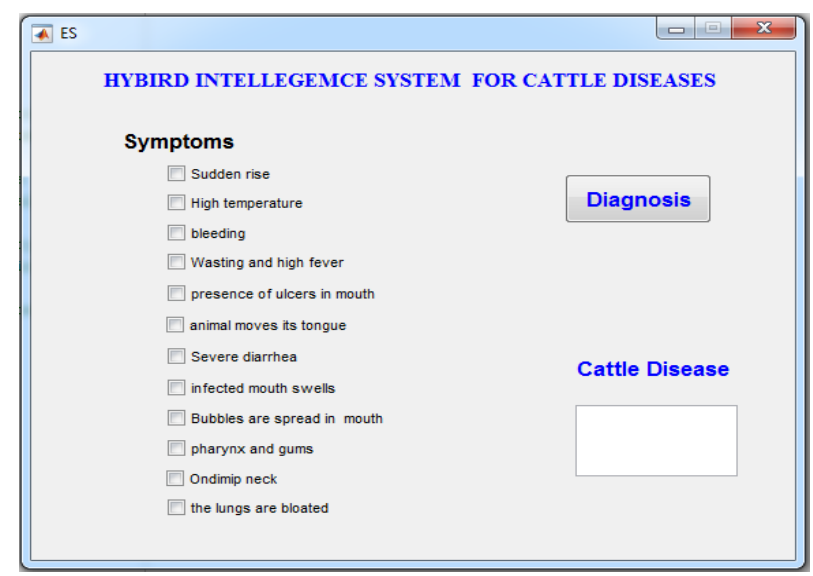

Fig. 3. Home page of expert system 
Treatment Diagnosis page as shown in figure 4, the Disease present in cattle as complained by the complaint. The appropriate drug is diagnosed.

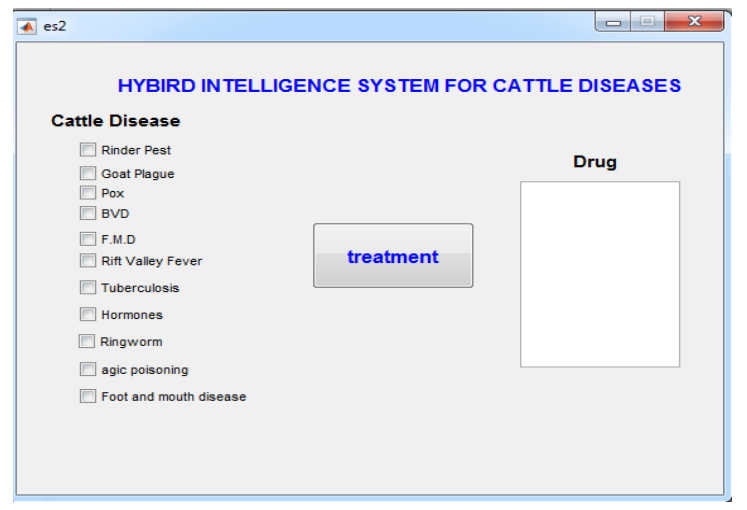

Fig. 4. Treatment Diagnosis Page

\section{CONCLUSION}

This paper is focused on decision-making for diagnosing cattle diseases. The system is an integrated expert system with Neural Network technical; this work produces hybrid intelligence techniques. The expert system makes intelligent decisions to diagnose cattle diseases based on their symptoms. And the neural network is classifying the treatment states. The proposed system introduces diagnosis to help doctors improve their reliability, speed, and accuracy in diagnosing diseases. The combines the advantages of two techniques by constructing a novel strategy for inference engine, which decreases complexity and time, the suggested system is more efficient and reliable than Artificial Intelligent ways.

\section{References}

[1]. Muhammad Akram1, Ismail Abdul Rahman, Irfana Memon, ," A Review on Expert System and its Applications in Civil Engineering" International Journal of Civil Engineering and Built Environment Vol.1, No.1, 2014; ISSN 2289-6317.

[2] Gu, Y. "Cattle Disease Diagnostic System (CaDDiS). Available at "http://vie.dis.strath.ac.uk/vie/CaDDiS/docs/Project_Team.html. Retrieved on January, 2012.

[3] M Alagappan \& M. Kumaran ,2013," Application of Expert Systems in Fisheries Sector - A Review" Research Journal of Animal, Veterinary and Fishery Sciences ISSN 2320 - 6535.

[4] Marques Helcio L. A._\& Boock Marcello," Integrated Freshwater Prawn Farming:State-of-the-Art and Future Potential" eviews in Fisheries Science \& Aquaculture 24(3):264-293,DOI: 10.1080/23308249.2016.1169245, 2016.

[5] Babu M. Surendra Prasad \& Vikram Dara ,2011," FishDoc Expert System- Diagnosis of Fish Diseases Using ABC Algorithm \& PSOAlgorithms" International Journal of Advanced Research in Computer Science Volume 2, No. 6, Nov-Dec 2011.

[6] Wirhan Fahrozi ,Charles Bronson Harahap ,Andrian Syahputra ,Rahmadani Pane,2018," Expert System of Diagnosing Koi's Fish Disease by Certainty Factor Method" Conference: 6th International

Conference on Cyber and IT Service Management (CITSM) DOI: 10.1109/CITSM.2018.8674326, 2018.

[7] Robin Mahon, "Adaptation of Fisheries and Fishing Communities to the Impacts of Climate Change in the CARICOM Region" Prepared for the CARICOM Fisheries Unit, Belize City, Belize, as input to the planning process for the project Mainstreaming Adaptation to Climate Change (MACC) of the Caribbean Centre for Climate Change (CCCC) 2002. 
[8] Dzmitry Bahdanau, Kyunghyun Cho, and Yoshua Bengio." Neural machine translation by jointly learning to align and translate" arXiv preprint arXiv:1409.0473 (2014).

[9] Hao Yanchao" An End-to-End Model for Question Answering over Knowledge Base with Cross-Attention Combining Global Knowledge www.nlpr.ia.ac.cn /cip/ liukang/liukang PageFile/ ACL2017-Hao.pdf. ,2017

[10] Wang Yan ," atwo-stage hybrid model by using artificial neural networks as feature construction algorithms" International Journal of Data Mining \& Knowledge Management Process (IJDKP) Vol.8, No.6, November 2018.

[11] C.-F. Tsai and J.-W. Wu, "Using neural network ensembles for bankruptcy prediction and credit scoring," Expert systems with applications, vol. 34, no. 4, pp. 2639-2649,2008.

[12] Abbas Sheikhtaheri \& Farahnaz Sadoughi \& Zahra Hashemi Dehaghi," Developing and Using Expert Systems and Neural Networks in Medicine: A Review on Benefits and Challenges" transactional processing systems J Med Syst (2014) 38:110 DOI 10.1007/s10916-014-0110-5.

[13] Zeinab Abrishami, Hamid Tabatabaee," Design of A Fuzzy Expert System And A Multi-Layer Neural Network System For Diagnosis Of Hypertension" Bulletin of Environment, Pharmacology and Life Sciences Bull. Env. Pharmacol. Life Sci., Vol] October 2015: 138-145 ,2015 Academy for Environment and Life Sciences, India Online ISSN 2277-1808.

[14] Zamsuri Ahmad at el, "Web Based Cattle Disease Expert System Diagnosis with forward Chaining Method" International Conference on Environment and Technology (IC-Tech), , 2017.

[15] Ravuri Murali at el ,2018," Learning from the experts: From expert systems to machine-learned diagnosis models" Learning from the experts: Proceedings of Machine Learning Research 85:1-16, 2018.

[16] Batista L. Oliveira ," Fuzzy neural networks to create an expert system for detecting attacks by SQL Injection" The International Journal of forensic computer science DOI: $10.5769 / \mathrm{J} 201801001$ or http://dx.doi.org/10.5769/J201801001 2018.

[17] FARMERS YUKON,2008," Cattle Health Handbook" Canadian Food inspection Agency (CFIA) districk office .

[18] Mansourkhaki Ali ," Berangi Mohammadjavad, Majid Haghiri ," "Comparative Application of Radial Basis Function and Multilayer Perceptron Neural Networks to Predict Traffic Noise Pollution in Tehran Roads "Journal of Ecological Engineering (JEE) Vol. 20, Issue 7, 2019.

[19] Yue-Gang Songa, Yu-Long Zhoub*, Ren-Jie Han," Neural networks for stock price prediction" journal of Difference Equations and Applications Stock price prediction using 'networks, 2018.

[20] Yaser A. Jassim, Safwan O. Hasson, "Diagnosis Windows Problems Based On Hybrid intelligence systems" , Journal of Engineering Science and Technology, Vol. 8, No 5, 2013.

[21] BIJU T. SAYED, “Application of expert systems or decision-making systems in the field of education”, JOURNAL OF CONTEMPORARY ISSUES IN BUSINESS AND GOVERNMENT VOL. 27, NO. 3, 2021 